\title{
OPTIMAL REGULATION OF \\ MULTIPLY-REGULATED INDUSTRIES: \\ THE CASE OF PHYSICIAN SERVICES
}

John A. Rizzo

Jody L. Sindelar

Working Paper No. 4822

\section{NATIONAL BUREAU OF ECONOMIC RESEARCH 1050 Massachusetts Avenue \\ Cambridge, MA 02138 \\ August 1994}

Earlier versions of this paper were presented at the 1993 meetings of the Southern Economics Association and the 1994 meetings of the American Economics Association. We thank Tom Abbott, Michael Crew, Doug Staiger, and an anonymous reviewer for helpful comments and suggestions. This paper is part of NBER's research program in Health Economics. Any opinions expressed are those of the authors and not those of the National Bureau of Economic Research.

(C) 1994 by John A. Rizzo and Jody L. Sindelar. All rights reserved. Short sections of text, not to exceed two paragraphs, may be quoted without explicit permission provided that full credit, including (1) notice, is given to the source. 


\title{
OPTIMAL REGULATION OF \\ MULTIPLY-REGULATED INDUSTRIES: \\ THE CASE OF PHYSICIAN SERVICES
}

\begin{abstract}
This paper models the physician services market which is regulated by two government agencies. The Health Care Financing Administration (HCFA) sets Medicare physician fees through the newly implemented Resource Based Relative Value Scale (RBRVS). The Agency for Health Care Policy and Research (AHCPR) sets practice guidelines for quality.

We analyze welfare losses which occur when agencies fail to coordinate their regulatory activities. Specifically, we consider the welfare impacts for cost, quality, practice characteristics, and quantity of care.

Perceived ills in the market for physician services, such as excessive expenditures and overly intensive treatment, may be traced to coordination failures. Thus, even if physicians were to act as perfect agents for their patients, and even if moral hazard were to be eliminated, coordination failure could cause the critical problems associated with the physician services market to persist. Although the model is applied to the market for physician services, it can be readily generalized to other settings involving multiple regulators.
\end{abstract}

John A. Rizzo

Yale University School of Medicine

P.O. Box 208034

New Haven, CT 06510
Jody L. Sindelar

Yale University School of Medicine

P.O. Box 208034

New Haven, CT 06510

and NBER 


\section{Motivation}

This paper models physician services as a market regulated by two governmental agencies, each concerned with a different aspect of market performance. One branch of the government, the Health Care Financing Administration (HCFA), currently sets Medicare reimbursement rates while another branch, the Agency for Health Care Policy and Research (AHCPR), sets practice or quality standards for physicians' services. While the standards set are merely guidelines, not rules, there are potentially costly implications to physicians from ignoring the guidelines.

An important type of regulatory failure occurs when agencies neglect to coordinate their actions. A growing body of research has found that coordination failures confound government efforts to implement optimal public policies (Coate 1992; Hansen and Stuart 1989: Kotlikoff 1987; Veall 1986; Baron 1984). These studies have typically focused on coordination failures between the public and private sectors. ${ }^{1}$ Our analysis examines coordination failures among regulatory agencies involved in different aspects of regulation within a given industry; respectively, price and quality regulation.

Given the varied institutional contexts in which multiple regulation occurs, formal representations may be most insightful when tailored to the specifics of each industry (Bernheim and Whinston 1986). ${ }^{2}$ In the case of the regulation of the physician services market, coordination failures occur when two agencies, one charged with price regulation, the other with setting medical practice guidelines, fail to take full account of each other's actions and goals. Although the basic model may be generalized to a number of settings, the physician services industry provides a particularly vivid example, given the current policy concerns about the cost and quality of medical care.

1 Baron (1984) is an exception to this pattern. He examines coordination failures between an agency concerned with regulating pollution emissions of a firm (the Environmental Protection Agency) and a public utility regulator who sets the firm's price.

2 Bernheim and Whinston investigate issues of the nature and existence of equilibrium in a purely abstract model of multiple regulation. However, as the authors note, "this task is made difficult by the proliferation of highly varied institutional contexts in which common agency appears" (p. 925). 
The remainder of the paper is diviled into 5 parts. Part 1 discusses the current regulatory environment under Medicare. Part 2 presents a model of optimal practice guidelines and physician reimbursement. Part 3 solves the model for the socially optimal case. Part 4 compares outcomes under coordination failure to the social optimum. In particular, the implications of coordination failures for cost, quality, medical practice characteristics, and quantity of care are derived. These are the salient outcomes of concen for health care regulatory agencies and for society. Part 5 summarizes the results and discusses their policy implications.

\section{Institutional background}

Medicare payments to physicians are now set by HCFA according to the recently implemented Resource Based Relative Value Scales (RBRVS). Practice guidelines are continuing to be developed by AHCPR. These guidelines set standards and try to affect the quality and appropriateness of care.

\section{A. Practice guidelines}

With the establishment in 1989 of the Agency for Health Care Policy and Research (AHCPR), the federal government made the development of practice guidelines an important component of health care regulation. AHCPR has initiated work on 16 practice guidelines. The Institute of Medicine and many other health care organizations are concurrently involved in guideline development?

Guidelines may be developed in a variety of ways. AHCPR is funding research on outcomes assessments to aid in the development of guidelines for specific procedures. More common methods than engaging in original research to develop guidelines are use of literature reviews of available scientific evidence and/or expert panels.

3 Over 50 health care organizations are actively involved in the development of practice guidelines. These organizations include professional groups, third-party payers, hospitals, academic medical centers, health maintenance organizations, independent researchers, and malpractice insurers (Physician Payment Review Commission 1992, p. 222). 
Guidelines may focus on diagnosis (diagnostic guidelines), evaluation of individual services (service guidelines), or appropriate treatment regimens for specific conditions (management guidelines). The first two types of guidelines identify illness and evaluate specific medical technologies or services, respectively. Management guidelines, however, prescribe appropriate treatments for an entire episode of care for a patient with a given medical condition. At present, AHCPR is devoting the vast majority of its efforts to the development of diagnostic and management guidelines (Physician Payment Review Commission (1992).

Such guidelines may have significant effects on physician behavior. First, they may lead physicians to rethink the type and level of care deemed appropriate. Second, deviations from the guidelines may impose costs on the physician, such as anxiety or increased malpractice exposure.

\section{IB. Reimbursement}

The Resource Based Relative Value Scale (RBRVS), effective as of January 1, 1992, is part of Medicare's recent effort to implement a physician fee schedule. The RBRVS computes "relative

1 The three main types of guidelines, diagnosis, management, and service, have been described in a recent Physician Payment Review Commission Report to Congress (1992) as follows:

Diagnostic guidelines are targeted at evaluating patients with particular symptoms (such as chest pain) for the presence of diseases that would benefit from iniervention (such as angina or esophagitis). They are also used to guide the screening of asympiomatic populations for early stages of disease (to detect, for example, hypertension or diabetes).

Management guidelines cover the evaluation and treatment of patients who are known to have certain conditions. Examples are guidelines dealing with low back pain or benign prostatic hypertrophy.

Service guidelines are organized around particular diagnostic and therapeutic procedures (such as chest X-ray, colonoscopy, appendectomy, or administration of hepatitis vaccine), presenting appropriate and inappropriate indications for their use (Physician Payment Review Commission 1992, p. 214). 
values" of physicians' services across specialties. It factors into the relative values the physician's time, the complexity of services, practice costs, and opportunity costs of medical training.

The RBRVS approach is designed to base reimbursement on the costs of providing care, rather than on actual charges, which was the previous approach (Hsiao 1988; Hadley 1991). By itself, the RBRVS is not a fee schedule. However, once relative values have been computed, an actual fee schedule is obtained by multiplying the RBRVS by a conversion factor. Although intended to address market imperfections in the physician services market, RBRVS has drawn considerable criticism from economists. ${ }^{5}$

\section{A model of reimbursement and practice guidelines}

The model presented below applies to the physician services market, especially with regard to the Medicare sector. Physician fees (prices) are set by HCFA, while AHCPR establishes practice guidelines. In this initial formulation of the model, government agencies engage in non-cooperative behavior. Cost control is a common objective of each agency. ${ }^{6}$ For the price setter (HCFA), practice attributes that affect patient access to and satisfaction with care are additional concerns; for the guideline setter (AHCPR), quality of care matters in addition to cost.

3 Noll (1991), for example, has argued that such problems as the arbitrary nature of allocating joint costs, and reliance on "an administrative process to construct a competitive equilibrium in the structure of physician prices" (p. 381) renders the RBRVS approach highly questionable.

6 Cost control has long been a prominent objective of the Health Care Financing Administration. Garber and Wagner (1991) have argued that cost containment should be an important component in the development of practice guidelines as well. They argue that the public

... expects that the resulting guidelines will not only improve the quality of medical care but will also reduce health care costs. (p. 53)

The authors also illustrate how failure to take cost considerations into account will lead to wasteful health care expenditures. 
Each agency is assumed to take the physician's profit maximizing behavior into account in setting price and guidelines. The implications of this model are then compared to the social optimum. In the social optimum, both agencies cooperate to promote quality and other characteristics, while controlling cost.

We assume that there is a single payer, Medicare, ${ }^{7}$ which sets the reimbursement rates for physician services and pays the entire bill for Medicare patients." As patients incur no out-of-pocket expenses for their care, their demand for care is insensitive to price. This simplifying assumption is reasonable given that: 1) the vast majority of physicians accept Medicare reimbursement as payment in full, 2) copayments are relatively small and 3) balance-billing amounts are smaller still. ${ }^{9}$

We further assume that patients have difficulty judging the appropriateness of medical treatment. Thus, the physicians alone determine the course of treatment in our model.

\section{A. Search model}

In this model of the physicians' services market, there are many (M) physicians who compete for patients, and numerous $(\mathrm{N})$ consumers who search for appropriate physicians. As the cost of

7 Although there is a single payer, Medicare does not exercise its potential monopsony power. Instead, it sets price with a view to constraining costs while promoting access.

- Alternatively, our model applies to the case where a national health insurance system is introduced, so that there is only one payer (government), but separate governmental branches set prices and establish practice guidelines. This is a likely situation in some of the health care reform scenarios.

- Gillis, Lee, and Willke (1992) report for example that almost $83 \%$ of Medicare Part B claims are accepted on assignment, so that no balance billing occurs in these cases. The authors also note that average copayments per claim were less than 28 dollars (in 1991 dollars), while balance billing amounted to less than 7 dollars per claim.

In reviewing balance billing during the mid-1980s, Zuckerman and Holahan (1991) concluded that "balance billing is likely to impose little, if any financial burden on the vast majority of Medicare beneficiaries" (p. 166). Under the recently implemented Medicare fee schedule, the amount by which the balance bill may exceed Medicare covered charges is restricted. Thus. the importance of balance billing has fallen further since the time period examined by Zuckerman and Holahan. While 2 percent of Medicase beneficiaries incurred total annual balance bills over $\$ 500$ in 1988 , virtually no patients will incur balance bills of this amount under the Medicare fee schedule (Physician Payment Review Commission 1992). 
care is paid for entirely by Medicare there is no price competition. Physicians compete for patients through non-price competition, in this case, by offering practice attributes that consumers value. ${ }^{10}$ These attributes enhance the attractiveness and accessibility of the physician." This search model is based on an earlier model due to Satterthwaite $(1979,1985)$. As in Satterthwaite (1979), we assume that physicians and consumers are homogeneous. However, consumers have different preferences over the attributes offered by physicians. One consumer may prefer physicians $\mathrm{j}$; another will prefer physician i. However, instead of Satterthwaite's price competition, our model has non-price competition in the form of medical practice attributes.

The model posits physicians as being in short run equilibrium..$^{12}$ In this steady state, however, patients may leave their current physician in favor of alternative ones. Patients may leave for demographic reasons such as individuals changing their area of residence. Some patients may also search for new physicians because they are not satisfied with the attributes of their current physicians and want to search for ones who will appeal to their particular tastes.

For an equilibrium to exist, for each physician, the expected number of patients entering the practice equals the expected number departing. Following Satterthwaite $(1979,1985)$, define $v_{i}$ as the probability that a randomly selected consumer from physician i's current practice will come to the physician for an office visit within a week. ${ }^{13}$ We assume that $v_{i}$ is an increasing function of the

10 That patients seek desirable attributes is supported in the literature. Surveys indicate that consumers desire attributes such as convenient location of practice, the availability of a physician answering service or other coverage at all times, an accessible and friendly demeanor by the physician toward his patients, good condition of facilities, and so on (Crane and Lynch 1988; MacStravic 1987).

1" While certain of these attributes may serve as indicators of the physician's technical skills, they are unlikely to be particularly informative signals of quality. For attributes to serve as quality signals, the marginal cost of producing attributes must fall the higher is physician quality, so that higher quality physicians would typically provide more attributes. However, this does not necessarily seem to be the case in this market.

12 The short run is defined as a period of time during which physician supply is fixed.

13 The time horizon is arbitrary. 
attributes physician i provides, $A_{i}$. The physician $i$ therefore expects to have $v_{i} N_{i}$ patient visits per week.

Define $s_{l}$ as the probability that a randomly chosen member of physician i's practice will decide to leave that practice in any given week, and $w_{1}$ as the probability that a randomly chosen consumer who has quit another's practice will join physician i's practice. It is assumed that $s_{i}$ is decreasing in $A_{i}$, and increasing in the attributes offered by all other physicians. Further, $w_{i}$ is increasing in $A_{i}$, and decreasing in all $A$ save for the ith physician. This leads to the equilibrium condition:

(1) $\quad s_{i} N_{i}=w_{1} \sum_{\substack{j=1 \\ j=i}}^{M} s_{j} N_{j}$.

Satterthwaite (1979) has shown that this equilibrium condition implies that the number of patients physician $i$ expects to receive, $\mathrm{N}_{\mathrm{i}}$, is a decreasing function of his or her price. A symmetric argument implies that $N_{i}$ is increasing in attributes $A_{i}$.

\section{B. Physician behavior}

We model physician behavior as consisting of sequential stages. In the first stage, physicians set the level of attributes to attract patients. In the second stage, given that the attributes level is already determined, physicians observe their patients' medical needs and decide how to treat them.

Provision of Attributes. In deciding upon the level of attributes to provide, the physician considers the cost of and expected return on various levels of attributes. Attributes are costly to provide and costs are increasing in the level of attributes. The expected return from providing more attributes is two-fold: first is the increased probability of visits $\left(v_{i}\right)$ per patient and second is the expected increase in the number of patients $\left(\mathrm{N}_{\mathrm{j}}\right)$. Each additional visit that the physician provides is valued by the physician at the rate of profits per visit, $\pi$, that he or she expects to receive. Profits per visit will depend positively on the price $P$ the physician receives under Medicare. Profits will 
also depend upon the level of treatment the physician expects to provide to patients, $T$. Wilh new patients arriving and some established patients leaving, the physician is uncertain in advance as to what level of care will be needed. We assume that the physician bases the expected treatment ievel on the treatment level currently provided to established patients. ${ }^{14}$ Thus, we may write expected profits per visit as $\pi=\pi(\mathrm{P}, \mathrm{M})$.

Given expected profits, the representative physician ${ }^{15}$ chooses attributes to:

$$
\max \pi(P, T)[v(A) N(A)]-g(A),
$$

$$
\begin{aligned}
& \text { where } N(A)=\quad \begin{array}{l}
\text { the perceived number of patients the physician can obtain as a } \\
\text { function of attributes } A, d N / d A>0 ; \text { and }
\end{array} \\
& g(A)=\quad \begin{array}{l}
\text { costs of providing attributes, } \mathrm{dg} / \mathrm{dA}>0 \text {, and other terms are as } \\
\text { defined above. }
\end{array}
\end{aligned}
$$

Maximizing (2) with respect to A yields $A$ as an increasing function of $P .{ }^{16}$ Individually, the physician perceives that he can obtain more patients, the higher the level of attributes offered. Since physicians are identical, they all increase attributes in response to a price increase in the same way. Because the stock of patients is fixed, however, a higher price does not lead to a higher number of patients treated per physician in equilibrium. In equilibrium, physicians treat an equal, fixed

${ }^{14}$ Since, as noted earlier, all patients are identical in our model save for their preferences over physician attributes, physicians' ex-ante expectations about the treatment levels required will equal actual treatment levels chosen ex-post.

13 Since all physicians are assumed to be homogeneous, subscripts denoting specific physicians are deleted from the remainder of the analysis for notational convenience.

16 The second order sufficiency conditions for a maximum guarantee that $\mathrm{DA} / \mathrm{dP}>0$. To see this, define $T T=\pi(P, T)[v(A) N(A)]-g(A)$. Derive the first-order condition for maximizing $T T$, and differentiate this expression with respect to $A$ and $P$. Rearranging terms yields: $d A / d P=-\left(d^{2} T T / d A d P\right) /\left(d^{2} T T / d A^{2}\right)$. The denominator is positive by the second order condition for a maximum, while $\mathrm{d}^{2} \mathrm{TT} / \mathrm{dAdP}=(\mathrm{d} \pi / \mathrm{dP})(\mathrm{dv} / \mathrm{dA})(\mathrm{dN} / \mathrm{dA})>0$. Hence, $\mathrm{dA} / \mathrm{dP}$ $>0$. This formulation is similar to that of Dorfman and Steiner (1954), where attributes in this model plays a role similar to advertising in their model. 
number of patients $(\mathrm{N} / \mathrm{M})$. The only effect of the price increase is to raise the equilibrium level of attributes provided.

Since each physician is providing a level of attributes that maximizes his or her net income, given the attributes provided by every other competitor, this is an equilbrium solution. Also, because we assume symmetry among physicians and patients, the equilibrium will preserve such symmetry, as Satterthwaite (1979) has noted.

Treatment levels. Given the physician's patient load and level of attributes, physicians now observe patient illness severity and decide how to treat them. ${ }^{17}$ Physicians are assumed to choose the level of care that maximizes profits per patient visit. The level of care they choose is a function of, among other things, the price that HCFA sets and the guideline that AHCPR sets. Thus, the physician's objective may be written as:

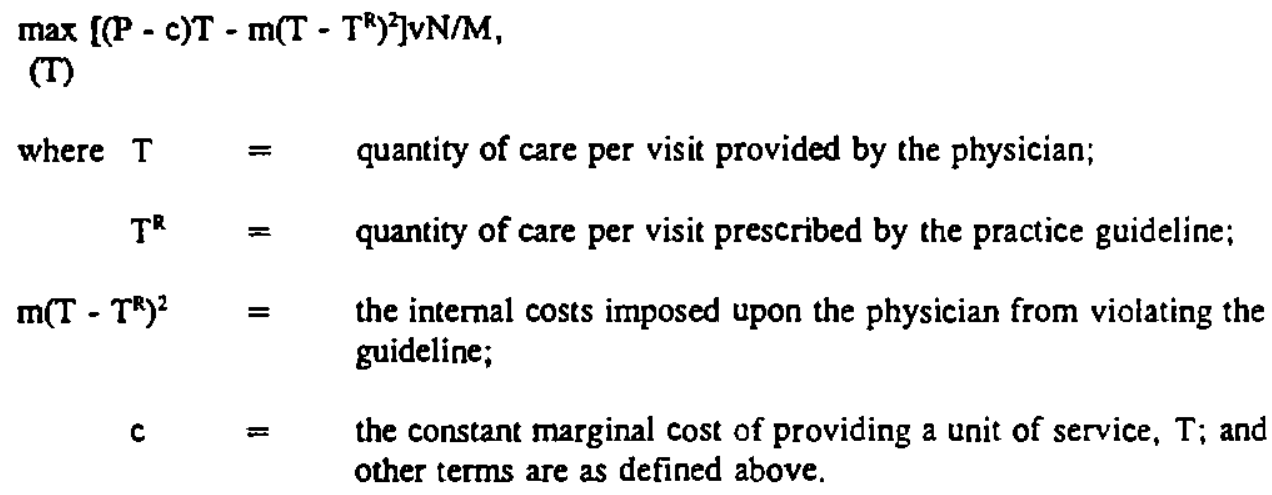

17 Once physicians have obtained their patients, they may have the incentive to renege on the attributes they offered to entice them. To the extent that attributes take the form of capital investments, they may be sunk costs which cannot be recovered. Even if it were possible to renege on promised attributes, however, physicians depend on long term relationships with their patients, and value their reputations in the community. Breaking their implicit contract with patients to provide a certain set of attributes is unlikely to be a wise strategy, as it may cause them to lose patients and send a bad signal to other potential clients. Thus, we assume that physicians to not renege on their offered attributes ex post. 
The first term in brackets in equation (3) is simply revenue less production cost per visit. ${ }^{\text {is }}$

Physicians receive fee-for-service payment at a rate of $\mathrm{P}$ per unit of $\mathrm{T}$. The second term measures the practice costs imposed upon the physician from violating the standard. The number of patients served is fixed in equilibrium (recall that only attributes increase with price).

Costs to the physician that arise from deviating from the standard can come in many forms, including psychic costs of deviating from delivering the best or most appropriate level of care, ${ }^{19}$ increased office-related expenditures (e.g., engaging in additional recordkeeping to justify their departures from the guidelines), ${ }^{20}$ increased involvement in medical malpractice litigation, and costs of responding to managed care inquiries (e.g., filling in extra forms and talking to managed care representatives). In addition, there may be opportunity costs incurred in the form of foregone benefits associated with compliance, such as exemption from utilization review or other regulations. The implications of practice guidelines for medical malpractice is a subject of growing concern (Physician Payment Review Commission 1992).

The solution to (3) gives the physician's profit maximizing level of services as a function of price, practice guidelines, and other parameters:

(4) $\quad T=(P-c) / s+T^{R}$, where for notational convenience we define $s=2 m$.

18 The physician also has fixed expenses in the form of providing attributes $(\mathrm{g}(\mathrm{A})$ ). This term would merely drop out of equation (2), as fixed costs do not affect the physician's decision at this point. Thus, we omit such costs for ease of exposition.

19 See McGuire and Pauly (1991) for a discussion of psychic costs associated with demand inducement. Coleman (1990), more generally, discusses internal sanctions that individuals place on themselves if they deviate from social nomns.

20 Evidence suggests that physicians engage in a significant amount of defensive medicine (Reynolds, Rizzo, and Gonzalez 1987; Institute of Medicine 1989a, 1989b). It is also conceivable that physicians whose practice patterns deviate substantively from guidelines may be subject to greater malpractice insurance premiums. 


\section{C. Regulators' objectives}

AHCPR's obiectives. AHCPR is charged with setting practice guidelines $\left(T^{R}\right)$ to promote quality of care; it does so by establishing guidelines on quantity of care per visit. Increasingly, however, the Agency is being urged to take cost considerations into account when setting the guidelines (Garber and Wagner 1991; Physician Payment Review Commission 1992). ${ }^{21}$ Hence, we assume that AHCPR seeks to minimize costs from providing less than the maximum quality of care and treatment costs per patient served. This goal may be written as:

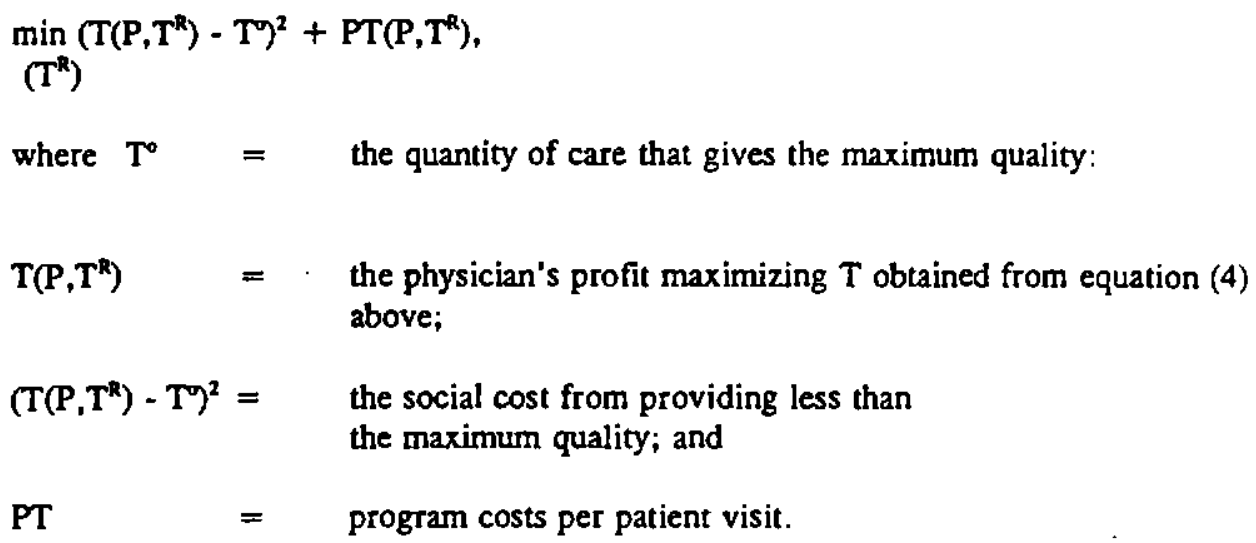

AHCPR recognizes that quality of care does not increase with quantity of $T$ over the entire distribution of treatment intensities. While increasing in quantity at first, beyond some point $T^{\circ}$, quality declines as problems such as iatrogenic infections, unnecessary surgical procedures or overly

21 Recently, the Physician Payment Review Commission has explicitly recommended that AHCPR pay attention to cost considerations as well as quality in guideline development:

Practice guidelines should be constructed to help improve the value of health care by addressing its cost as well as quality. The Agency for Health Care Policy and Research (AHCPR) should give greater priority to developing practice guidelines...that could potentially reduce the amount of resources spent on unnecessary medical care. AHCPR should specify the elements that should be incorporated in guidelines so that they can be used to improve both the effectiveness and the efficiency of care. All federally sponsored guidelines should be required to contain these elements to the greatest extent possible (Physician Payment Review Commission 1992). 
invasive diagnostic tests occur. A variety of such problems have been found to be associated with increases in delivery of care beyond a certain point (Brook and McGlynn 1991).

Thus, $T^{0}$ is that level of services which maximizes quality of care. This is the gold-standard for quality of care- the quality of care that consumers would desire if services were costless to them. Losses to society from less than the maximum quality of care relate to deviations of $T$ from the quality maximizing level of care $\left(\mathrm{T}^{\circ}\right)$. To capture these features while retaining analytical tractability, we specify a quadratic loss function.

As noted earlier, $\mathrm{T}$ represents the quantity of services per medical visit (i.e., the number of tests, treatments, or medications). As each service is reimbursed at the rate P, PT equals cost of the care and the charge to Medicare per visit.

Equation (5) says that AHCPR seeks to minimize the sum of program expenditures ${ }^{n}$ and the social costs from providing less than the maximum quality. These social costs are higher the further away is $\mathrm{T}$ from $\mathrm{T}^{\circ}$.

BCFA's objectives. We assume that HCFA desires to control costs while maximizing physician accessibility and patient satisfaction. HCFA sets the reimbursement rate, $P$, knowing that attributes that patients value increase in $P$, but that costs rise as well. These objectives may be expressed as:

(6) $\quad \min \left(P-P^{0}\right)^{2}+P T\left(P, T^{R}\right)$,

(P)

where $\mathrm{P}^{\circ} \quad=\quad$ the price that elicits the utility maximizing level of attributes; and

2 Since the total number of patients treated by all physicians is fixed, nothing is gained by multiplying ( 5 ) by the fixed number of patients treated. Without loss of generality, we may regard (5) as setting this number equal to 1 . With $M$ physicians treating $N / M$ patients each, total prograrn costs will be found by multiplying PT by the constant $N$. 
$\left(P-P^{q}\right)^{2}=$ the one-sided social cost function from providing less than the utility maximizing level of care. ${ }^{3}$

We refer to the expression $\left(\mathrm{P}-\mathrm{P}^{\mathrm{q}}\right)^{2}$ as a one-sided loss function because only the range $0<\mathrm{P}<$ $P^{\circ}$ is relevant: given that HCFA is concerned about cost control in addition to service quantity, $P$ will always be less than $P^{\circ}$.

This specification, while simple, captures the essence of the tradeoff faced by HCFA. ${ }^{24}$ In the case of Medicare, cost containment is undeniably an important consideration. Equation (6) says that HCFA seeks to minimize the sum of losses to patients from receiving less than the utility maximizing level of attributes, and treatment costs. As stated above, it is the cost consciousness guarantees that HCFA will always select a price below $\mathrm{P}^{0}$. $^{2 s}$

When price is below $\mathrm{P}^{\circ}$, however, social costs arise because attributes fall below the utility maximizing level, which occurs when $P=P^{\circ}$. Moreover, the further $P$ is below $P^{\circ}$, the greater the shortfall between actual and desired attributes, and the higher the social costs.

2 All prices and costs are taken to be expressed in terms of some numeraire good. If we were to drop this assumption, the square of the difference between dollar-denominated prices would be in units of dollars-squared. We assume that the square of this difference is instead expressed in terms of a numeraire. Thus, $\mathrm{P}, \mathrm{P}^{\circ}$, and all other parameters and variables in this model should be thought of as pure numbers, not as dollar-denominated quantities.

24 Note that this loss function does not measure the full social costs of non-optimal delivery of care, however. The full social costs include losses from receiving less than the maximum quality (given by the expression (T(P,TR) - $\left.T^{2}\right)^{2}$ described above) as well from receiving less than the utility maximizing level of attributes. The term $\left(P-P^{\circ}\right)^{2}$ only measures the latter social costs, which result from HCFA's pricing decisions.

25 $\mathrm{P}$ may be regarded as a 'bliss' point. Beyond this point, the marginal utility of attributes is zero, or even negative (negative attributes could occur with fawning physicians and nurses, or information overload). 


\section{Solving the model}

\section{A. The social optimum}

Society is concerned about the provision of attributes, quality, and the cost of care. In the non-cooperative game, each agency is concerned about costs yet otherwise their goals diverge. In the cooperative game, agencies coordinate their behavior to minimize the sum of program costs, and social costs from providing less than the quality maximizing quantity of care and less than the utility maximizing level of attributes per patient served.

In the cooperative case, given physician behavior described by (4), $\mathrm{P}$ and $\mathrm{T}^{\mathrm{R}}$ are chosen to:

$$
\min _{\left(P, T^{R}\right)}\left(P-P^{\circ}\right)^{2}+\left(T\left(P, T^{R}\right)-T^{\circ}\right)^{2}+P T\left(P, T^{R}\right) .
$$

Substituting from (4) for $T$, and minimizing with respect to $P$ and $T^{R}$ gives the optimal levels for $P$ and $T^{R}$ :

(8) $\quad \mathrm{P}^{*}=2\left(2 \mathrm{P}^{\circ}-\mathrm{T}^{\circ}\right) / 3$;

(9) $\quad \mathrm{T}^{\mathrm{R}^{*}}=\mathrm{c} / \mathrm{s}+(4 \mathrm{~s}+2) \mathrm{T}^{\circ} / 3 \mathrm{~s}-(4+2 \mathrm{~s}) \mathrm{P} / 3 \mathrm{~s}$,

where $\mathrm{P}^{*}$ denotes the equilibrium price for the cooperative game and $\mathrm{T}^{\mathrm{R}^{*}}$ denotes the equilibrium guideline. Substinting (8) and (9) into (4) gives the equilibrium level of care:

(10) $T^{\circ}=2\left(2 T^{\circ}-\mathrm{P}^{\circ}\right) / 3$.

Note that positive values for $\mathrm{P}^{*}$ and $\mathrm{T}^{\circ}$ require that $\mathrm{P}^{\circ}>\mathrm{T}^{\circ} / 2$ and $\mathrm{T}^{\circ}>\mathrm{P}^{\circ} / 2$. This we interpret as a requirement that $\mathrm{P}^{\circ}$ and $\mathrm{T}^{\circ}$ are "not too far apart". ${ }^{26}$

\section{Coordination failure}

This section compares the effects of coordination failures to the social optimum.

Coordination failure stems from non-cooperative behavior between agencies. AHCPR seeks to

26 Notice that $T^{*}$ will always be less than $T^{\circ}$. To see this, note from equation (10) that $T^{*}$ achieves its maximum value as $\mathrm{P}^{\circ}$ approaches its minimum permissible value, which must exceed $T^{\circ} / 2$. When $\mathrm{P}^{\circ}=\mathrm{T}^{\circ} / 2, \mathrm{~T}^{\circ}=\mathrm{T}^{\circ}$. For all values of $\mathrm{P}^{\circ}$ greater than $\mathrm{T}^{\circ} / 2$, we must have $\mathrm{T}^{\circ}<\mathrm{T}^{\circ}$. 
minimize (5) while HCFA seeks to minimize (6). Each agency observes the solution to the physician's problem (4).

In choosing price, HCFA substitutes for $T$ from equation (4) and then minimizes (6) with respect to $P$, taking $T^{R}$ as given. The solution to this minimization problem gives HCFA's price as a function of $T^{R}$. This is HCFA's reaction function:

$\mathrm{P}=\left(2 \mathrm{~s} \mathrm{P}^{\circ}+\mathrm{c}\right) / 2(1+\mathrm{s})-s \mathrm{~T}^{\mathrm{R}} / 2(1+\mathrm{s})$.

In setting its guideline, AHCPR substitutes for $T$ from (4), and then minimizes (5) with respect to $T^{R}$, taking $P$ as given. The solution to this problem yields AHCPR's reaction function:

$T^{R}=c / s+T o-(2+s) P / 2 s$

The Cournot equilibrium is found by solving (11) and (12) for $\mathrm{P}$ and $\mathrm{T}^{\mathrm{R}}$, respectively:

$$
T^{R C}=c / s+4(1+s) T /(2+3 s)-(4+2 s) P^{0} /(2+3 s),
$$

where the superscript " $\mathrm{C}$ " indicates the equilibrium solution given coordination failure. Substituting (13) and (14) into (4) gives the equilibrium actual level of care:

$$
\mathrm{T}^{\circ}=\left[(4 s+2) \mathrm{T}^{\circ}-2 \mathrm{~s}^{0}\right] /(2+3 s) \text {. }
$$

Having derived the equilibrium levels for price, and the actual level of care provided, we are ready to compare the implications of coordination failures for the outcomes of interest.

\section{A. Price/Autributes}

The effects of coordination failure on price and hence attributes may be found by subtracting equation (8) from (13) yielding:

$$
\mathrm{P}^{c}-\mathrm{P}^{-}=-4\left(2 \mathrm{P}^{\circ}-\mathrm{T}^{\circ}\right) / 3(2+3 s)<0 .
$$

Thus, coordination failure leads to a lower price and fewer attributes than are socially optimal. The reason is that, under non-cooperative behavior, HCFA fails to recognize the indirect effect of price on the attributes associated with the provision of care. HCFA chooses a lower price than is socially optimal because it fails to recognize that a higher price increases the patient-desired attributes of care. 
The lower price in the noncooperative case increases the social costs from providing less than the utility-maximizing level of attributes of care. ${ }^{27}$

\section{B. Quartity}

The net effect of coordination failure on quantity of services is the difference between equations (15) and (10):

$$
\mathrm{T}^{*}-\mathrm{T}^{*}=2\left(2 \mathrm{P}^{\circ}-\mathrm{T}^{*}\right) / 3(2+3 \mathrm{~s})>0 \text {. }
$$

Thus, with coordination failure, the quantity of services exceeds the social optimum.

The changes in price and practice guidelines under coordination failure relative to the social optimum exert competing influences on the actual quantity of services provided. On the one hand, the lower price under coordination failure decreases the amount of care provided, ceteris paribus. On the other hand, the lower price increases the need to set a high practice guideline, and in fact the guideline under coordination failure is higher than in the cooperative case. ${ }^{28}$ The higher guideline exerts a positive effect on actual treatment levels. The latter effect dominates, so that quantity of care is higher in the cooperative case.

\section{C. Quality}

The implications of coordination failure for quality of care are straightforward. First, observe that $T^{c}$ is always less than $T^{\circ}$. This, together with the fact that $T^{c}>T^{*}$ (see equation (17)), implies that the quantity of care is closer to $T^{\circ}$ under coordination failure than under cooperation. Thus,

\footnotetext{
In Under cooperative behavior, the indirect effect of HCFA's pricing decision is taken into account: HCFA realizes that a higher price raises the profit maximizing intensity of care, as can be seen from equation (4). Since $T^{\circ}$ is always less than $T^{\circ}$ (see footnote 26), a higher price also raises quality of care under cooperative behavior. Thus, in the cooperative situation, HCFA realizes that a higher price serves the socially valuable function of lowering the social costs from inappropriate care. This creates an additional incentive to raise price in the cooperative case.
}

2. Subtracting the socially optimal practice guideline (9) from the equilibrium guideline under coordination failure (14) and simplifying terms yields: $(4+2 s)\left(2 \mathrm{P}^{\circ}-\mathrm{T}^{\circ}\right) / 3 \mathrm{~s}(2+3 \mathrm{~s})>0$ (recall that positivity of $\mathrm{P}$ requires that $\mathrm{P}^{\circ}>\mathrm{T}^{\circ} / 2-$ see equation (8) in the text). 
coordination failure increases the actual quality of care received, but raises it above the social optimum, $\mathrm{T}^{*}$.

4D. Cost

Straightforward calculations yield:

$$
\mathrm{P}^{C} \mathrm{~T}^{C^{\circ}}-\mathrm{P} \mathrm{T}^{*}=4\left[2 \mathrm{P}^{\circ}-\mathrm{T}^{0}\left[\mathrm{P}^{\circ}(4+12 s)-\mathrm{T}^{\circ}(8+15 \mathrm{~s})\right] / 9 \mathrm{~s}(2+3 \mathrm{~s})^{2}\right.
$$

Whether cost exceeds or falls short of the social optimum depends upon the ratio $\mathrm{P}^{\circ} / \mathrm{T}^{\mathrm{o}}$ : high values of this ratio lead to excessive cost relative to the social optimum, while low values lead to the opposite result. ${ }^{29}$ In particular, we have:

$$
\begin{aligned}
& \mathrm{P}^{C} \mathrm{~T}^{\mathrm{C}}-\mathrm{P}^{\circ} \mathrm{T}^{*}>0 \text { as } \mathrm{P} / \mathrm{T}^{\circ}>(8+15 \mathrm{~s}) /(4+12 \mathrm{~s}) .^{30} \\
& << \\
& =\quad=
\end{aligned}
$$

Thus, if society desires a high level of attributes per unit of medical treatment, $\mathrm{P}^{\circ} / \mathrm{T}^{\circ}$ will be high and coordination failure will lead to excessive expenditures. On the other hand, if attributes are little valued, coordination failure leads to insufficient expenditure relative to the social optimum. One interpretation of this has interesting implications. It seems likely that attributes will be much more valued in advanced economies ( $\mathrm{P}^{\circ} / \mathrm{T}^{\circ}$ will be relatively large), than in underdeveloped ones, where no frills medical care is de rigueur. This, in turn, suggests that coordination failure may work differently in developed and underdeveloped economies, leading to excessive health care expenditures in the former, but insufficient spending in the latter. An interesting issue is how different reform bills

29 High values of $\mathrm{P} / \mathrm{T}^{\circ}$ may be considered to represent a high value placed on desirable attributes of care relative to medical quality of care. Thus low $\mathrm{P} / \mathrm{T}^{\circ}$ may represent the "no fringes" provision of health care while higher values of $\mathrm{P}^{\circ} / \mathrm{T}^{\circ}$ represent higher provision of attributes relative to medical quality per se.

* Notice that, as $s$ becomes arbitrarily small, the range of permissible values for $\mathrm{P} / \mathrm{T}^{\circ}$ for which $\mathrm{P}^{C} \mathrm{~T}^{\mathrm{C}}-\mathrm{P}^{\mathrm{T}} \mathrm{T}^{*}>0$ becomes smaller and smaller. There will always be a permissible range for $\mathrm{P}^{\circ} / \mathrm{T}^{\circ}$ over which $\mathrm{P}^{\mathrm{lC}} \mathrm{T}^{\mathrm{IC}}>\mathrm{P} \mathrm{T}^{-}$, however. This is because the second order conditions for a social optimum require that $s>0$. But $s>0$ allows $\mathrm{P}^{1 C} \mathrm{~T}^{1 \mathrm{C}}>\mathrm{P}^{\prime} \mathrm{T}^{*}$ for values of $\mathrm{P}^{\circ} / \mathrm{T}^{\circ}$ between 1.25 and 2 (the precise cutoff point depending on the value of $\mathrm{s}$ ), which is in the permissible range for $\mathrm{P} / \mathrm{T}^{\circ}$. 
would value attributes relative to medical quality as this would, under the likely scenario of coordination failure, affect expectations about expense.

\section{Conclusion}

The model we have presented examines coordination failures arising when two different arms of government implement policies designed to affect the physician services market. Coordination failure among governmental agencies has implications for price, attributes, quantity, quality, and cost

of care. For example, coordination failure raises the quantity and quality of service above the social optimum, while price and patient-desired attributes of care are less than their socially optimal levels.

Although excessive costs and treatment levels are popularly attributed to moral hazard and/or self-interested behavior by physicians, our model traces such problems to coordination failure among regulatory agencies as well. Thus, even if physicians were perfect agents and health insurance contracts were to eliminate moral hazard, problems of excessive costs and an over provision of care could persist.

The basic approach of the model, which emphasizes social costs of coordination and information failures, applies well to other health care markets. For example, some health care markets- such as the market for renal dialysis- are regulated by both state and federal governments, yielding the same sorts of issues posed here (Brown, Smith, and Sindelar 1992). Other industries to which the insights of our approach would apply include public utilities, banking, and agriculture.

The results of our model suggest that cooperation and information exchange among regulatory branches should be pursued. Cooperation may be promoted through informal channels or more formal arrangements such as consolidating the activities of regulatory agencies into larger departments. With dramatic changes in the organization and finance of health care on the horizon. these issues may assume even greater importance. 


\section{$\underline{\text { References }}$}

Baron D. (1984). "Noncooperative regulation of a nonlocalized externality." Rand Journal of Economics 16, 553-568.

Bernheim B., and Whinston M. (1986). "Common agency." Econometrica 54, 923-942.

Brook R. and McGlynn E. (1991). "Maintaining quality of care." In: Health Services Research: Key to Health Policy (E. Ginzberg, ed). Cambridge, MA: Harvard University Press.

Brown E., Smith D., and Sindelar J. (1992). "Can we regulate the quality of care?: the case of dialysis in Connecticut." American Journal of Kidney Disease 19, 609-613.

Coate S. (1992). "Altruism, the samaritan's dilemma, and government transfer policy." Working Paper, Department of Economics, University of Pennsylvania.

Coleman J. (1990). Foundations of Social Theory Cambridge. MA: Harvard University Press.

Crane F, and Lynch J. (1988). "Consumer selection of physicians and dentists: An examination of choice criteria and cue usage." Journal of Health Care Marketing 8, pp. 16-19.

Dorfman, R. and Steiner, P. (1954). "Optimal advertising and optimal quality" American Economic Review 44, pp. 826-36.

Garber A. and Wagner J. (1991). "Practice guidelines and cholesterol policy." Health Affairs 10, pp. 52-66.

Gillis K., Lee D., and Willke R. (1992), "Physician-based measures of Medicare access." Inquiry 29, pp. 321-331.

Hadley J. (1991). "Theoretical and empirical foundations of the Resource-Based Relative Value Scale." In: Regulating Doctors' Fees (H. Frech ed). Washington, DC: AEI Press, pp. 97125.

Hansen L. and Stuart C. (1989). "Social security as trade among living generations." American Economic Review 79, pp. 1182-1195.

Hsiao W. et al. (1988). "Resource Based Relative Values." Journal of the American Medical Association October 28, pp. 2347-2360.

Institute of Medicine. (1989a). Medical Professional Liability and the Delivery of Obstetrical Care. Volume 1. Washington, DC: National Academy Press.

Institute of Medicine. (1989b). Medical Professional Liability and the Delivery of Obstetrical Care, Volume 2. Washington, DC: National Academy Press.

Kotlikoff L. (1987). "Justifying public provision of social security." Journal of Policv Analysis and Management 6, pp. 674-689. 
References, cont.

MacStravic R. (1987). "Manageable evidence in medical care marketing." Journal of Health Care Marketing 4, pp. 52-59.

McGuire, T. and Pauly M. "Physician response to fee changes with multiple payers" $\underline{\mathrm{J}}$. of Health Economics 10, 1991, pp. 385-410.

Noll R. (1991). "On regulating prices for physicians." In: Regulating Doctors' Fees (H. Frech ed). Washington, DC: AEI Press, pp. 381-386.

Physician Payment Review Commission. (1992). Annual Report to Congress. Washington, DC.

Reynolds R., Rizzo J., and Gonzalez M. (1987). "The cost of medical professional liability." Journal of the American Medical Association 257, pp. 2776-2781.

Satterthwaite M. (1979). "Consumer information, equilibrium industry price, and the number of sellers." Bell Journal of Economics 10, pp. 483-502.

Satterthwaite M. (1985). "Competition and equilibrium as a driving force in the health services sector," pp. 239-267. In: Managing the Service Economy: Prospects and Problems ( $R$. Inman, ed). New York: Cambridge University Press.

Veall M. (1986). "Public pensions as optimal social contracts." Journal of Public Economics 31, 237-251.

Zuckerman S. and Holahan J. "The role of balance billing in Medicare physician payment reform." In: Regulating Doctors' Fees (H. Frech ed). Washington, DC: AEI Press, pp. 143-169. 